\title{
Posterior Cranial Fossa
}

National Cancer Institute

\section{Source}

National Cancer Institute. Posterior Cranial Fossa. NCI Thesaurus. Code C33361.

The infratentorial compartment of the cranial cavity. Its boundaries are formed by the sphenoid bone, temporal bone, and parietal bone, and it contains the cerebellum and brain stem. 